\title{
Evaluation of Antioxidant Activity of Aqueous and Ethanolic Extracts of Stem Bark of Xylopia villosa Chipp (Annonaceae)
}

\author{
Kouame Yao Yves ${ }^{1, *}$, Okpekon Aboua Timothée ${ }^{2}$, Niamketchi Gilles Léonce ${ }^{3}$, Gbassi Komenan Gildas ${ }^{4}$, \\ Yapi Houphouët Félix ${ }^{1}$ \\ ${ }^{1}$ Laboratory of Pharmacodynamics Biochemical, UFR Biosciences, Felix Houphouet Boigny University, Cote d'Ivoire \\ ${ }^{2}$ Laboratory of Organic Chemistry and Natural Substances, UFR Sciences of Structures of Matter and Technology, Felix Houphouet \\ Boigny University, Cote d'Ivoire \\ ${ }^{3}$ Biochemistry Laboratory and Food Science, Felix Houphouet Boigny University, Cote d'Ivoire \\ ${ }^{4}$ Laboratory of Analytical Chemistry, General and Inorganic Chemistry, Faculty of Science Pharmaceutical and Biological, Felix \\ Houphouet Boigny University, Cote d'Ivoire
}

Copyright $\subset 2016$ by authors, all rights reserved. Authors agree that this article remains permanently open access under the terms of the Creative Commons Attribution License 4.0 International License

\begin{abstract}
This study aims to evaluate antioxidant activity of aqueous and ethanolic extracts of Xylopia villosa stem bark. The quantitative study of polyphenols showed that ethanolic extract $(75.00 \pm 3.82 \mathrm{~g} / \mathrm{L} \mathrm{EqAG})$ contains more than the aqueous extract $(55.83 \pm 1.67 \mathrm{~g} / \mathrm{L} \mathrm{EqAG})$. It is the same for the quantitative analysis of total flavonoids where ethanolic extract $(135.00 \pm 1.44 \mathrm{~g} / \mathrm{L} \mathrm{EqQ})$ contains more than the aqueous extract $(115.00 \pm 6.61 \mathrm{~g} / \mathrm{L} \mathrm{EqQ})$. The antioxidant activity in vitro showed that the extracts neutralize DPPH and ABTS $+{ }^{\circ}$ with enhanced activity of the ethanolic extract. The ethanolic and aqueous extracts of Xylopia villosa causing 50\% inhibition (IC50) of the DPPH radical gave concentrations of $10.50 \pm 0.24$ and $24.50 \pm 0.18$ $\mathrm{mcg} / \mathrm{ml}$ respectively for ethanol extract and aqueous extract. On the reduction of radical $\mathrm{ABTS}+{ }^{\circ}$, aqueous extract caused a reduction of the radical cation ABTS $+7.82 \pm 0.17$ micromol TE / L while the ethanol extract reduced by 10.52 \pm 0.27 micromol TE / L. Evaluation of antioxidant activity in vivo of xylopia villosa revealed that this is the ethanol extract $(9.17 \pm 0.48 \mathrm{mmol} / \mathrm{L}$ TBA-MDA) which offset the concentration of TBA-MDA adduct more than the aqueous extract (22.67 $\pm 0.33 \mathrm{mmol} / \mathrm{L}$ TBA-MDA). Concerning the total antioxidant activity, ethanolic extract reduced iron III to Iron II more than aqueous extract. After this study, it appears that the ethanolic extract has better antioxidant activity in vitro and in vivo that the aqueous extract.
\end{abstract}

Keywords Xylopia villosa, Antioxidant, In vitro, Carrageenan

\section{Introduction}

Plants are vital to biodiversity and serve primarily to human welfare [1]. They have a cultural importance and economic potential in the food, health care, energy, clothing and housing construction. Relationships between plants and humans have existed for long dates [2]. Medicinal plants are valuable resources for the majority of rural populations in Africa, where more than $80 \%$ of these populations use them to ensure their health care [3]. In addition, these plants are invaluable resources for the pharmaceutical industry [4].

The Ivorian flora in 1979 [1] revealed five thousand species including Xylopia villosa. Xylopia are a large pantropical genus comprising about 150 species of which around thirty are found in mainland tropical Africa and 25 species in Madagascar. Xylopia villosa is a tree whose wood, hard and durable enough, is used to make building poles and tool handles [5]. Powder or macerated of Xylopia villosa stem bark is used in traditional medicine to treat various diseases including colds and headaches. The ground seeds are applied on ulcers and boils for healing [5]. It produces a monoterpene essential oil whose composition is dominated by sabinene or $\beta$-ocimene [6]. Recently, the study of the chemical composition, the acute toxicity and evaluation of anti-inflammatory activity of Xylopia villosa stem bark was done [7a, 7b]. However, the antioxidant activity of this plant doesn't exist in the literature. In order to explore this activity, the general objective of this study be to evaluate the antioxidant activity of aqueous and ethanolic extracts of Xylopia villosa stem bark. To do this, a spectrophotometric determination of total polyphenols and total flavonoids was performed on said extracts. Then, an in vitro study was carried out through the tests of DPPH (2, 2'-diphenyl-1-picrylhydrazyl) and ABTS (2, 2'-azinobis-3-ethylbenzothiazoline-6-sulfonic acid). Finally, an in vivo study was conducted through tests of TBARS (reactive substances to thiobarbituric acid) and FRAPS 
(Ferric Reducing Antioxidant Power).

\section{Materials and Methods}

\subsection{Plant Material}

Xylopia villosa stems bark were harvested in June 2014 at the National Floristic Center of Felix HOUPHOUET BOIGNY University where can be found a sample recorded at the number 14712 .

\subsection{Preparation of Extracts}

The stems bark of Xylopia villosa were dried for four weeks. The drying process of the stems barks of Xylopia villosa was done in the absence of light to avoid the principle of the clear phase of photosynthesis which is for the plant (Xylopia villosa) to capture the light energy Photons and to transmit it by way of the electrons charged with this energy, to a chain of electron acceptors (molecules with variable oxidoreduction potentials). Then the dried stem bark of Xylopia villosa made powder using an electric grinder IKAMAG RCT ${ }^{\circledR} .100$ grams of powder of Xylopia villosa were macerated for 24 hours in 1 liter of ethanol (ethanol and distilled water mixture: 70/30). The macerated obtained was then filtered twice on white cotton and once on Whatman filter paper $\mathrm{N}^{\circ} 4$. The filtrate obtained in $70 \%$ ethanol was evaporated to dryness at reduced pressure at temperature of $40^{\circ} \mathrm{C}$ using a rotary evaporator type Buchi 161 Water Bath. About aqueous extract preparation, 100 grams of Xylopia villosa stem barks powder were added to 100 milliliters of boiling distilled water. Just like ethanolic preparation, the resulting mixture was filtered twice on white cotton and once on Whatman filter paper $\mathrm{N}^{\circ} 4$. The filtrate obtained is preserved at temperature of $40^{\circ} \mathrm{C}$ in an oven for drying.

\subsection{Reagents, Solvents and Drugs for Antioxidant Activity}

Folin-Ciocalteu (Merck Co. Germany); calcium carbonate; gallic acid and distilled water were used to make the spectrophotometric assay of total polyphenols. Sodium nitrite, aluminum chloride, sodium hydroxide and quercetin (Sigma Chemical Co.; St. Louis, USA) were used for the determination of total flavonoids.

DPPH (2, 2'-diphenyl-1-picrylhydrazyl); quercetin; ethanol and methanol were used to assay the anti-radical activity.

The 2,2'-azinobis-3-ethylbenzothiazoline-6-sulfonic acid; potassium persulfate; methanol and distilled water were used for the assay ABTS.

Trichloroacetic acid 20\%; the thiobarbituric acid $0.2 \%$; n-butanol (Merck Co. Germany); sulfuric acid and 1,1,3,3-tetramethoxypropane were used to determine the concentration of adduct TBA-MDA in the sample.

TPTZ (2, 4, 6-tripyridyl-triazine); acetate buffer $\mathrm{pH}=3.6$; the ferric chloride; ferrous sulfate and hydrochloric acid were used for determining the total antioxidant power. Carrageenan (HiMedia Lab. Pvt. Ltd. Mumbai, Indian) was used to create stress. Other products were supplied by Sigma Aldrich France.

\subsection{Experimental Animals}

Thirty(30) albino rats of wistar strain of either sex, aged nine (9) weeks of average weight $176 \pm 0.78$ grams, were used to evaluate in vivo antioxidant activity. The rats were housed in cages, fed pellets made by FACI ${ }^{\circledR}$ (Ivory Coast Food Manufacturing) and had free access to water. The temperature of the room was constant and was $21 \pm 1^{\circ} \mathrm{C}$ with a relative humidity of $54 \pm 3 \%$ and a 12 hours light and 12 hours of darkness. The care and the conditions of animals' treatment are in conformity with Guidelines of the Organization for Economic Cooperation and Development [8].

\subsection{Blood Collection}

For this study, the total volume of blood which can be taken with an animal (example of the rat or the mouse) is not enough. Thus, the number of taking away was distributed on several animals. We did not take with an animal more than $20 \%$ of its total blood volume. The volume of taken blood took into account the weight and the total volume of blood available to the animal. About $3 \mathrm{~mL}$ of blood was collected from puncturing the retro orbital sinus from anesthetized rats. The blood was centrifuged at $2000 \times \mathrm{g}$ for $10 \mathrm{~min}$ to separate serum. This serum was kept at $-20^{\circ} \mathrm{C}$ until the analysis [9].

\subsection{Antioxidant Activity}

\subsubsection{Polyphenolic Components}

\subsubsection{Determination of Total Phenolic Contents:}

Total phenols were determined by Folin-Ciocalteu method, as indicated by Wood and al [10].

\subsubsection{Estimation of Total Flavonoids Content:}

The total flavonoids content was determined according to the method of Marinova and al [11].

\subsection{In Vitro Antioxidant Activity}

\subsubsection{DDPH Radical Assay:}

The free radical scavenging activity by aqueous and ethanolic (ethanol and distilled water mixture: 70/30) extracts and vitamin $\mathrm{C}$ were measured with the DPPH method as indicated by Parejo and al [12]. The percentage inhibition of DPPH radical by the samples was calculated according to formula of Yen and Duh [13]. The IC50 value was determined from the plotted graph of scavenging activity against the different concentrations of Xylopia 
villosa extracts, which is defined as the total antioxidant necessary to decrease the initial DPPH radical concentration by $50 \%$. The measurements were triplicated and their scavenging effect was calculated based on the percentage of DPPH scavenged.

\subsubsection{ABTS Radical Assay:}

The method used is based on the capacity of the compounds (aqueous and ethanolic extracts) to reduce the cation radical ABTS + o (2,2'-azinobis-3-ethylbenzothiazoline-6-sulfonic acid). The test was performed according to the method described by Choong and al [14]. The cation radical ABTS $+{ }^{\circ}$ was produced by reaction of $8 \mathrm{mM} \mathrm{ABTS}(87.7 \mathrm{mg}$ in $20 \mathrm{~mL}$ of distilled water) and $3 \mathrm{mM}$ potassium persulfate $(0.0162 \mathrm{~g}$ in $20 \mathrm{~mL}$ distilled water) in a ratio $1: 1(\mathrm{v} / \mathrm{v})$. The mixture was then incubated in the dark at room temperature for 12 to 16 hours. This ABTS $+{ }^{\circ}$ solution was diluted with methanol so as to obtain a solution whose absorbance was $0.7 \pm 0.02$ at $734 \mathrm{~nm}$. Thus, a test sample of $3.9 \mathrm{~mL}$ of this diluted ABTS $^{\circ}+$ solution was added to $100 \mu \mathrm{L}$ of the compound (aqueous and ethanolic extracts) to be tested. After stirring, the mixture was incubated for 6 minutes in the dark $(\mathrm{T}=30$ $\pm 2{ }^{\circ} \mathrm{C}$ ). The residual absorbance of the ABTS $+{ }^{\circ}$ radical was then measured at $734 \mathrm{~nm}$ using the UV-visible spectrophotometer. A calibration line was made with the following Trolox concentrations: $0.375 \mu \mathrm{M} ; 0.5 \mu \mathrm{M}$; $0.625 \mu \mathrm{M} ; 1 \mu \mathrm{M} ; 1.125 \mu \mathrm{M}, 1.375 \mu \mathrm{M}$ and $1.5 \mu \mathrm{M}$. The tests were carried out in triplicate for each compound (aqueous and ethanolic extracts) and the results were expressed in $\mu$ mol Trolox equivalent per liter of extract ( $\mu \mathrm{mol}$ TE / L).

\subsection{In Vivo Antioxidant Activity}

\subsubsection{Experimental Design:}

Thirty (30) albino rats of wistar strain of either sex, were divided into five groups $(\mathrm{N}=6)$. The group 1 (control) received physiological saline while groups 2 and 3 received $200 \mathrm{mg} / \mathrm{kg}$ of aqueous and ethanolic extracts respectively. Groups 4 and 5 received vitamin $\mathrm{C}(100 \mathrm{mg} / \mathrm{ml})$ and physiological saline $0.9 \%$ respectively. One hour after drug injection, $0.2 \mathrm{ml}$ of the carrageenan solution at $1 \%$ was injected in the footpad of the right hind paw of each rat except the rats of the group 1. The injection of the carrageenan used to induce stress. After 5 hours, the blood of animals was removed with a Pasteur pipette at eye level, was centrifuged and the serum was used to perform the Lipid peroxidation assay and Total antioxidant power assay.

\subsubsection{Lipid Peroxidation Assay:}

Lipid peroxidation was determinated by Thiobarbituric Acid Reactive Substances (TBARS) method, as described by Satoh [15]. In an acid medium, at pH 2 to 3 and at $100^{\circ} \mathrm{C}$, a molecule of MDA is condensed with two molecules of TBA to form an absorbent colored complex at $532 \mathrm{~nm}$.

\subsubsection{Total Antioxidant Power Assay:}

The total antioxidant capacity of serum was determined by measuring its ability to reduce Iron III - Iron II by the FRAP (Ferric Reducing Ability of Plasma) test as described by Benzie and Strain [16].

\subsection{Statistical Analysis}

The values expressed as Mean \pm SEM from 6 animals. The statistical analysis was carried out using one way analysis of variance (ANOVA) followed by Dunnett's test, $\mathrm{P}<0.05$ was considered as significant.

\section{Results}

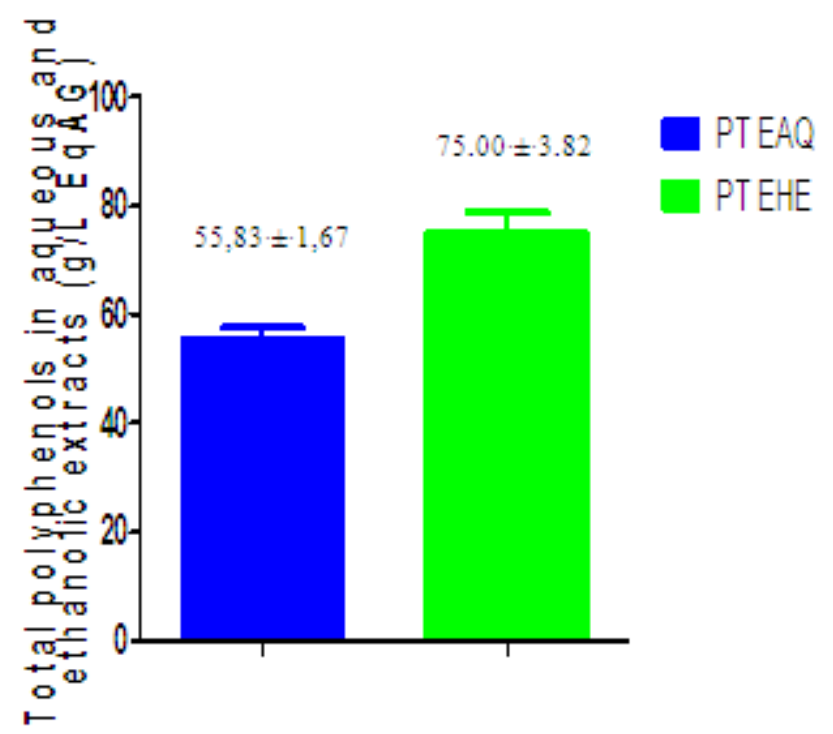

PT EAQ: Total polyphenols in aqueous extract PT EHE: Total polyphenols in ethanolic extract EqAG: Gallic acid equivalent

Figure 1. Total polyphenols in aqueous and Ethanolic extracts of Xylopia villosa In vitro antioxidant activity

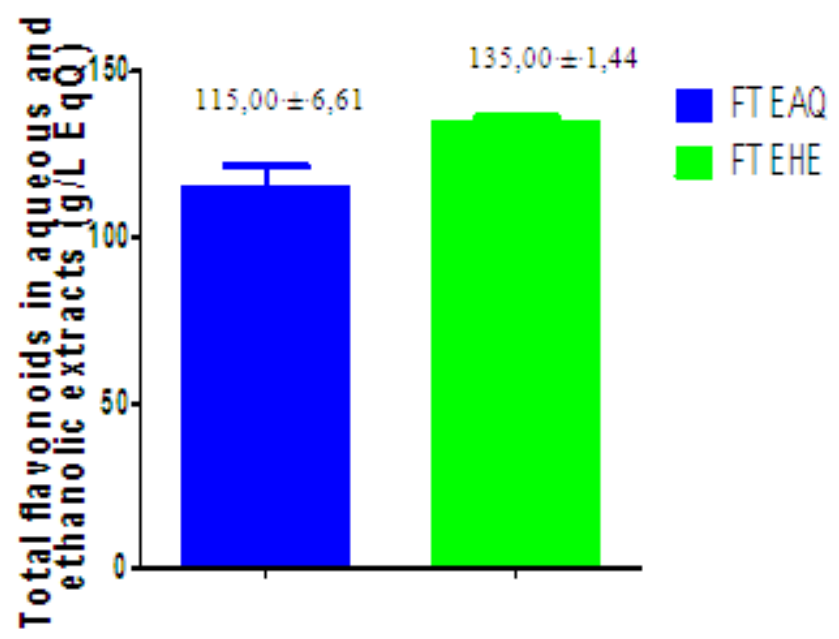

FT EAQ : Total flavonoids in aqueous extract FT EHE : Total flavonoids in ethanolic extract EqQ: Quercetin equivalent

Figure 2. Total flavonoids in aqueous and ethanolic extracts of Xylopia villosa stem bark 
Quantitative analysis of antioxidant components: Spectrophotometric analysis of polyphenols gave $55.83 \pm$ 1.67 and $75.00 \pm 3.82 \mathrm{~g} / \mathrm{L} \mathrm{Eq} \mathrm{AG} \mathrm{respectively} \mathrm{to} \mathrm{the}$ ethanolic extract of Xylopia villosa and the aqueous extract of Xylopia villosa (Figure 1).

Spectrophotometric analysis of total flavonoids showed that the ethanol extract of Xylopia villosa contained $135.00 \pm$ $1.44 \mathrm{~g} / \mathrm{L}$ EqQ while the aqueous extract of Xylopia villosa contained $115.00 \pm 6.61 \mathrm{~g} / \mathrm{L} \mathrm{EqQ}$ (Figure 2).

\section{In Vitro Antioxidant Activity}

DPPH test: The results of the antiradical activity of Quercetin and aqueous and ethanolic extracts of Xylopia villosa shown in Fig. 3. The antiradical activity increases with increasing concentration of Quercetin and the ethanolic extract Xylopia villosa. However, the anti-radical activity of the aqueous extract increases of 3.125 microgram $/ \mathrm{mL}$ (mcg/mL) to $25 \mathrm{mcg} / \mathrm{mL} .25 \mathrm{mcg} / \mathrm{mL}$ to 100. The graphical determination of the concentration of Quercetin, ethanolic and aqueous extracts of Xylopia villosa causing 50\% inhibition (IC50) of the DPPH radical yielded the values of $2.09 \pm 0.13 ; 10.50 \pm 0.24$ and $24.50 \pm 0.18$ $\mathrm{mcg} / \mathrm{ml}$ respectively for Quercetin, ethanolic extract and aqueous extract of Xylopia villosa. These results show that Quercetin has the best anti-radical activity, then the ethanolic extract and finally the aqueous extract.

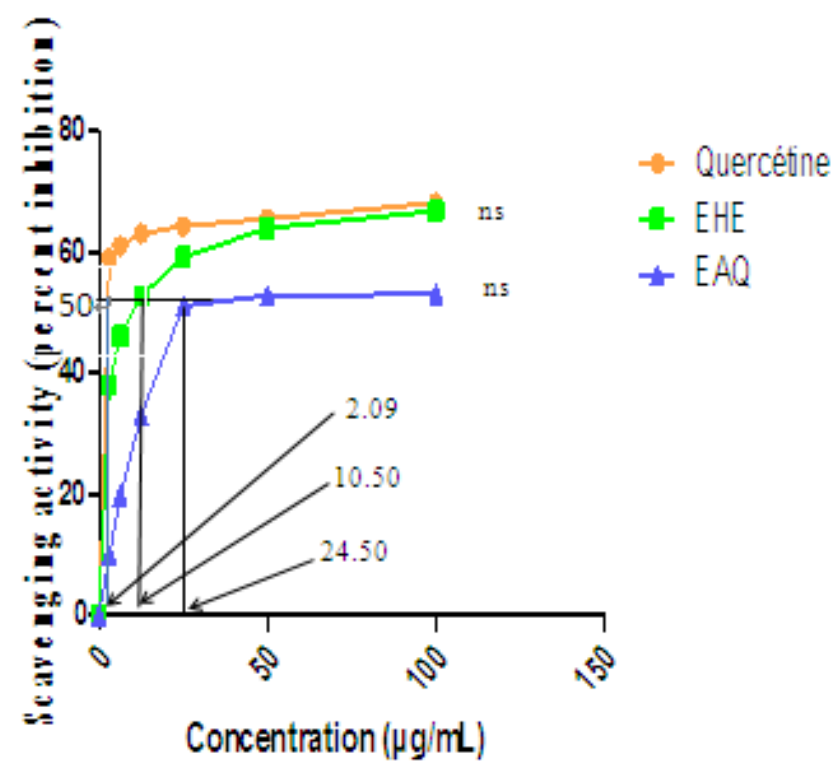

$\mathrm{P}>0.05$ : No significant difference (ns) between the ethanolic and aqueous extracts compared to quercetin (reference compound)

EAQ: Aqueous extract ; EHE : Ethanolic extract

Figure 3. Evolution of radical scavenging Activities of quercetin aqueous and ethanolic extracts of Xylopia villosa

ABTS radical assay: The ability of aqueous and ethanolic extracts to reduce the radical cation $\operatorname{ABTS}^{+\circ}\left(2,2^{\prime}\right.$-azinobis-3-ethylbenzothiazoline-6-sulfonic acid) is shown in Fig. 4. The aqueous extract inhibited the radical cation $\mathrm{ABTS}^{+} 7.82 \pm 0.17 \%$ while the ethanolic extract inhibited $10.52 \pm 0.27 \%$.

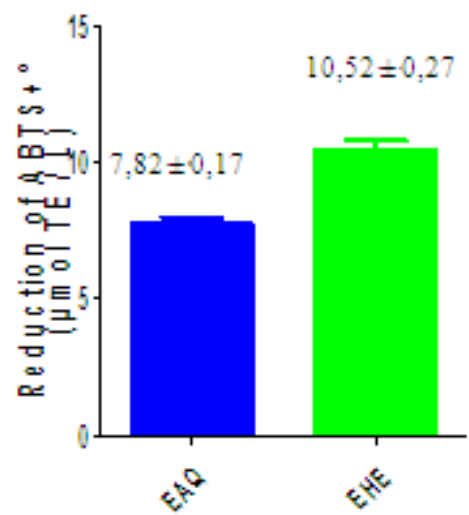

EAQ: Aqueous extract ; EHE : Ethanolic extract ; TE : Trolox équivalent

Figure 4. Reduction of radical cation $\mathrm{ABT} \mathrm{S}^{+\circ}$ by aqueous and ethsnolic extracts of Xylopia Villosa

\section{In Vivo Antioxidant Activity}

Concentrations of TBA-MDA adduct: The effect of aqueous and ethanolic extracts of Xylopia villosa and vitamin $\mathrm{C}$ on the concentration of TBA-MDA adduct (thiobarbituric acid - malondialdehyde) is shown in Fig. 5. The results obtained are $7.66 \pm 0.42 ; 25.83 \pm 0.40 ; 22.67 \pm$ $0.33 ; 9.17 \pm 0.48$ and $8.50 \pm 0.34 \mathrm{mmol} / \mathrm{L}$ TBA-MDA adduct. The concentration of TBA-MDA adduct batch intoxicated and not treated $(\mathrm{NaCl}+\mathrm{C})$ has increased and that of the group treated with the aqueous extract $(200 \mathrm{mg} / \mathrm{kg}$ ) body weight (bw).

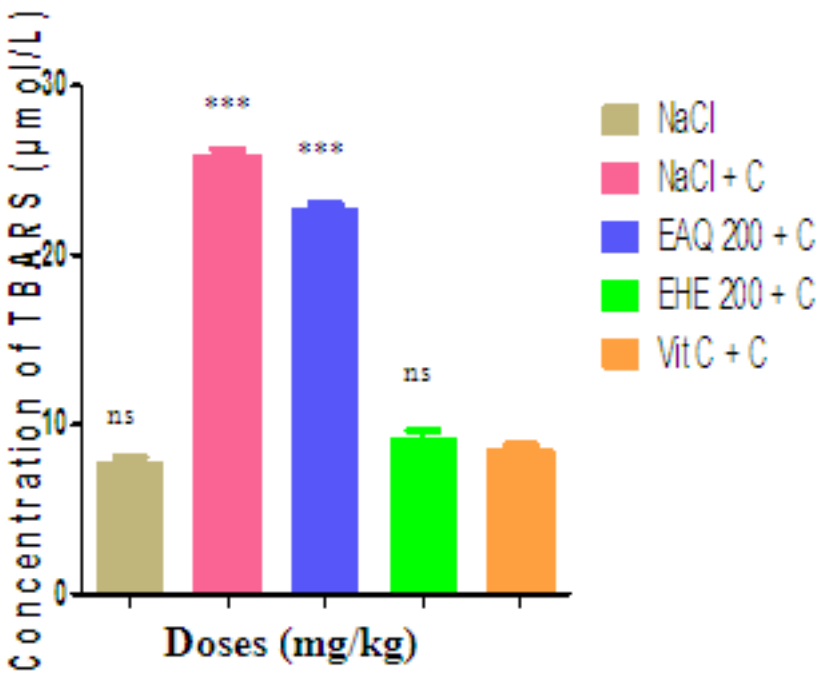

$* * * \mathrm{P}<0.001$ : Very highly significant difference between untreated intoxicated group $(\mathrm{NaCl}+\mathrm{C})$ and group treated with the aqueous extract (EAQ $200+C$ ) compared to vitamin C (reference compound).

$\mathrm{P}>0.05$ : No significant difference between the witness $(\mathrm{NaCl})$ and group treated with ethanolic extract (EHE $200+\mathrm{C}$ ) compared to vitamin C (reference compound).

$\mathrm{NaCl}$ : Sodium chloride; $\mathrm{NaCl}+\mathrm{C}$ : Sodium chloride + Carrageenan; EAQ $200+\mathrm{C}$ : Aqueous extract $(200 \mathrm{mg} / \mathrm{kg} \mathrm{bw})+$ Carrageenan; EHE $200+\mathrm{C}$ : thanolic extract $(200 \mathrm{mg} / \mathrm{kg}$ bw) + Carrageenan; Vit C + C: Vitamin C + Carrageenan

Figure 5. Evolution of concentrations of TBA-MDA adduct in samples of serum 
Total antioxidant power: The total antioxidant power of vitamin $\mathrm{C}$ and aqueous and ethanolic extracts of Xylopia villosa is illustrated in Fig. 6. The Iron II ion concentrations resulting from the reduction of Iron III is $4.00 \pm 0.26 ; 7.17 \pm$ $0.17 ; 10.67 \pm 0.33$ and $12.17 \pm 0.31$ micromol of Iron II /L respectively for $\mathrm{NaCl}$, the aqueous extract, ethanolic extract and vitamin $\mathrm{C}$ treated with carrageenan. The group $(\mathrm{NaCl}$ without carrageenan) recorded a concentration of $6.33 \pm 0.21$ micromol Iron II / L.

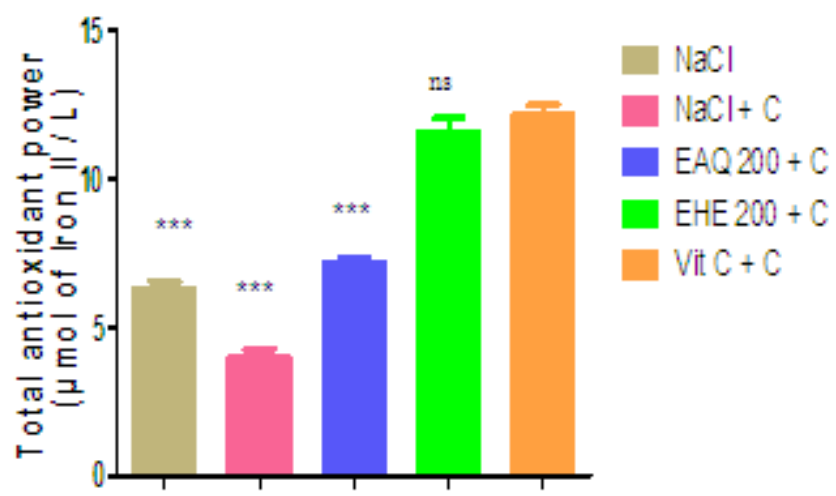

$* * * \mathrm{P}<0.001$ : Very highly significant difference between witness group $(\mathrm{NaCl})$, untreated intoxicated group $(\mathrm{NaCl}+\mathrm{C})$ and group treated with the aqueous extract (EAQ $200+\mathrm{C}$ ) compared to vitamin $\mathrm{C}$ (reference compound).

$\mathrm{P}>$ 0.05: No significant différence between group treated with ethanolic extract (EHE $200+\mathrm{C}$ ) compared to vitamin C (reference compound).

$\mathrm{NaCl}$ : Sodium chloride; $\mathrm{NaCl}+\mathrm{C}$ : Sodium chloride + Carrageenan;

EAQ $200+\mathrm{C}$ : Aqueous extract $(200 \mathrm{mg} / \mathrm{kg} \mathrm{bw})+$ Carrageenan

EHE $200+\mathrm{C}$ : Ethanolic extract (200 mg / kg bw) + Carrageenan;

Vit C + C: Vitamin C + Carrageenan.

Figure 6. Total antioxidant of vitamin $\mathrm{C}$ aqueous and ethanolic extracts of Xylopia villosa

\section{Discussion}

The quantitative analysis of aqueous and ethanolic extracts of Xylopia villosa stem barks showed that the ethanolic extract contains more than total polyphenols (75.00 $\pm 3.82 \mathrm{~g} / \mathrm{L}$ EqAG) and total flavonoids $(135.00 \pm 1.44 \mathrm{~g} / \mathrm{L}$ $\mathrm{EqQ})$ that the aqueous extract which contains $55.83 \pm 1.67 \mathrm{~g}$ $/ \mathrm{L}$ EqAG (total polyphenols) and $115.00 \pm 6.61 \mathrm{~g} / \mathrm{L}$ EqQ of total flavonoids This result is in agreement with that obtained by Bidie and al [17] who showed that the methanolic extract of D. benthamianus contains a high content of total phenols estimated at $70.17 \pm 0.84 \mathrm{mg}$ EAG $/ \mathrm{g}$ of extract.

Regarding the antioxidant activity in vitro, the method antiradical or free radical scavenging DPPH was used. The anti-radical activity results in an electron donating or proton reducing radical form DPPH hydrazyl to give the non-radical form hydrazyne. All substances with the ability to capture or neutralization of free radicals are called antioxidants [18]. The results show that the aqueous and ethanolic extracts of Xylopia villosa stem barks neutralize free radicals DPPH and $\mathrm{ABTS}^{+{ }^{\circ}}$ with a strong neutralization for the ethanolic extract. This anti-radical power could be due to the high content of total polyphenols. Indeed, polyphenols are endowed with antioxidant activity due to their redox properties [19] that allow them to neutralize free radicals by donating electrons or protons [20].

The Malondialdehyde (MDA) is used to estimate the damage caused by reactive oxygen species. One of the most commonly used markers for determining oxidative stress is malondialdehyde (MDA), which is a marker of lipoperoxidation. MDA is one of the end products of decomposition of polyunsaturated fatty acids under the effect of free radicals released during oxidative stress.

Reducing the concentration of TBA-MDA adduct is more pronounced for hydroethanolic extract than aqueous extract. This reduction of TBA-MDA adduct concentration is attributable to the total polyphenols present in the extracts of Xylopia villosa.

Similarly, the aqueous extracts and hydroéthanoliques of Xylopia villosa have shown their ability to reduce the iron ion 3 to iron ion 2 . This reducing capacity is more important for the ethanolic extract. The strong reductive capacity of the ethanolic extract is linked to its polyphenol concentration. According Yildirim and al [21], there is a link between the content of phenolic compounds and reducing power.

\section{Conclusions}

After this study, it appears that aqueous and ethanolic extracts of Xylopia villosa stem bark has antioxidant activity in vitro and in vivo. However, it is the ethanolic extract that has the best antioxidant activity in vitro and in vivo. The best activity is linked to the high content of total polyphenols. This study broadens the field of study of Xylopia villosa.

\section{REFERENCES}

[1] E.J. Adjanohoun, L. Ake-Assi. Contribution au recensement des plantes médicinales de Côte d'Ivoire. Ed. Centre national de floristique de l'Université Nationale de Côte d'Ivoire, 1: pp 23-30, 1979.

[2] A. Din, S.A.H. Bukhari, A. Salam, B. Ishfaq. Development of functional and dietetic beverage from bitter gourd. Internet Journal of Food Safety, Vol.13, 355-360, 2011.

[3] M.E. Mpondo, S.D. Dibong. Traditional knowledge on medicinal plants use by ethnic communities in Douala, Cameroon. European Journal of Medicinal Plants, 2(2): 159-176, 2012.

[4] A. Awono, O. Ndoye, K. Schreckenberg, H. Tabuna, F. Isseri, F. Temple. Production and marketing of safou in Cameroon and internationally: Market development issues, For. Trees Live lihoods, 12: 125-147, 2002.

[5] H.M. Burkill. The useful plants of west tropical Africa. Editions Royal Botanic Gardens, Kew, 960p, 1985.

[6] T.A. Yapi, J.B. Boti, C.A. Ahibo, A. Bighelli, Casanova, F. Tomi. Composition of leaf and stem bark oils of Xylopia villosa Chipp. Journal of Essential Oil Research, 24(3): 
253-257, 2012.

[7] Y.Y. Kouame, A.T. Okpekon, H.F. Yapi, K.G. Gbassi, Y.J. Assi, Y.K.F Kouakou. Phytochemical screening and acute toxicity study of Xylopia villosa (annonaceae) barks stems of aqueous and hydroethanolic extracts. European Journal of Pharmaceutical and Medical Research 3(6), 526-531, 2016.

[8] Y.Y. Kouame, A.T. Okpekon, H.F. Yapi, K.G. Gbassi. Evaluation of Anti-Inflammatory Activities of Aqueous and Ethanolic Extracts of Xylopia villosa (Annonaceae). Asian Journal of Biochemical and Pharmaceutical Research Issue 3 (Vol. 6), 2231-2560, 2016.

[9] OECD. Guideline for testing of chemicals: Acute oral toxicity-fixed dose procedure. OECD/OCDE 420, December 17, 2001. http://www.oecd.org/chemicalsafety/risk-assessme nt/1948362. pdf.

[10] OVF. Informations sur la Protection des Animaux. Prelevement de sang chez les rongeurs de Laboratoire et les lapins à des fins experimentales. Office Veterinaire Federal, No. 800.116-1.04, 1981.

[11] J.E. Wood, S.T. Senthilmohan, A.V Peskin. Antioxidant activity of procyanidin-containing plant extracts at different pHs. Food Chemistry, T.77, 155-161, 2002.

[12] D. Marinova, F. Ribarova, M. Atanassova, Total phenolics in bulgarian Fruits and vegetables. Journal of the University of Chemical Technology and Metallurgy, T.40, N³, 255-260, 2005.

[13] I. Parejo, C. Codina, C. Petrakis, P. Kefalas. Evaluation of scavenging activity assessed by $\mathrm{Co}(\mathrm{II}) /$ EDTA-induced luminal chemilunes-cence and DPPH (2,2-diphényl-1-pycryl -hydrazyl) free radical assay J Pharmacol Toxicol Method, 44 : 507-512, 2000.
[14] G.C. Yen, P.D. Duh, Scavenging effect of methanolic extracts of peanut hulls on free-radical and active-oxygen species. J. Agric. Food Chem., 42: 629-632, 1994.

[15] C. Choong, T.T. Van-Den, F. Roger, MC.F.L. Roger. Antioxidant activities, phenolic and beta-carotene contents of sweet potato genotypes with varying flesh colours. Food Chemistry103(3): 829-838, 2007.

[16] K. Satoh. Serum lipid peroxide in cerebrovascular disorders determined by a new colorimetric method. Clin. Chem. Acta, 90: 37-43, 1978.

[17] I.F.F. Benzie, J.J. Strain. The Ferric Reducing Ability of Plasma (FRAP) as a measure of antioxidant power: The FRAP assay. Anal. Biochem., 239: 70-76, 1996.

[18] A.P. Bidie, B.B. N'guessan, A.F. Yapo, J.D. N'guessan, A.J. Djaman. Activités antioxydantes de dix plantes médicinales de la pharmacopée ivoirienne. Sciences \& Nature. 8: 1-11, 2011.

[19] A.A Dehpour, M.A. Ebrahimzadeh, S.F. Nabavi, S.M. Nabavi. Antioxidant activity of methanol extract of Ferula assafoetida and its essential oil composition. Grasas Aceites, 60: 405-412, 2009.

[20] W. Zeng, S.Y. Wang. Antioxidant activity and phenolic compounds in selected herbs. J Agric Food Chem, 49: 5165-5170, 2001.

[21] C.W. Chen, C.T. Ho. Antioxidant properties of poyphenols extraxted from green tea and black tea. J Lipids, 2: 35-46, 1995.

[22] A. Yildirim, A. Mavi, A.A. Kara. Determination of antioxidant and antimicrobial activities of Rumex crispus L. extracts. J Agric Food Chem, 49: 4080-4089, 2001. 